\section{Abalone aquaculture struggles for foothold in Tomales Bay}

\author{
Paul G. Olin
}

Overharvesting and deterioration of coastal habitat have decimated California's once thriving abalone populations. The commercial abalone catch reached a record low of 224,000 pounds in 1996, down $90 \%$ from harvests in the 1960s. Most of the catch has been going to foreign markets, where prices have quadrupled over the past decade to $\$ 40$ per abalone. California's last major commercial abalone fishery was shut down in May when the Fish and Game Commission declared a moratorium on the harvesting of red abalone south of San Francisco. The commission had already stopped commercial harvesting of white, pink, green and black abalone.

With wild stocks clearly unable to meet the demand for abalone, commercial growers have begun to establish abalone farms in Tomales Bay and elsewhere along the California coast. Interest in abalone aquaculture first developed in the late 1960s, and Sea Grant provided research funding for some of the initial work on abalone spawning, larval rearing, settlement and culture. With this basic research foundation, abalone culture made the transition from research and development to commercial production. In 1995, abalone farmers produced around 250,000 pounds of live abalone, comparable to the amount commercially harvested from the wild.

As a new agricultural industry, abalone aquaculture practices are constantly evolving as growers encounter new problems. Polychaete worms are one of the most serious problems to surface recently. Two of these worms Polydora websteri and an unidentified sabellid worm from South Africa - have been found in locally cultured abalone.

These parasites can substantially reduce abalone growth rates and restrict shipment to international markets. Although they do not interfere with meat quality, the worms live in tubes within the abalone shell and interfere with shell growth and elongation. The challenge is to

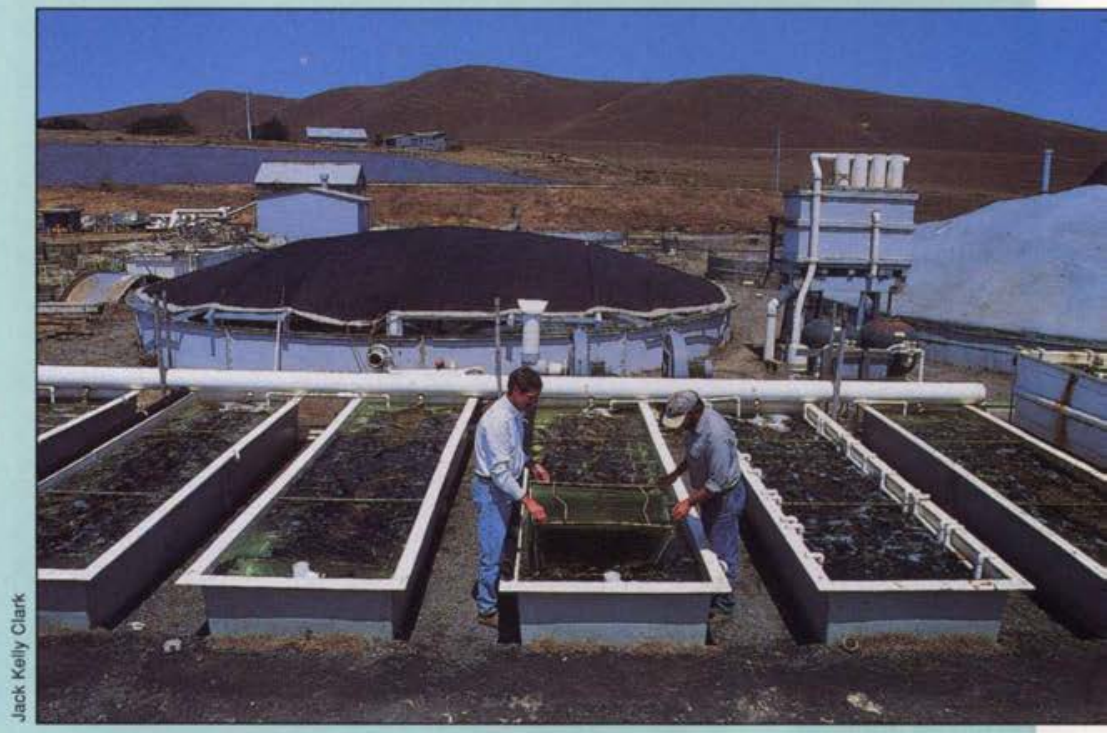

eliminate the polychaetes without seriously harming the abalone host. We are currently working at Bodega Farms, the Bodega Marine Lab and UC Santa Barbara to evaluate potential treatments. Possible approaches to polychaete control range from freshwater immersion to parasiticide applications.

This year's heavy winter storms delivered another major blow to abalone growers when freshwater runoff from the surrounding water-
UC marine advisor Paul Olin, left, confers with Peter Hain, a marine biologist and partner in Bodega Farms. The North Coast abalone farm produces seed stock for commercial grow-out operations throughout the world. Olin has evaluated several different abalone diets and has conducted experiments to control parasites in abalone culture.

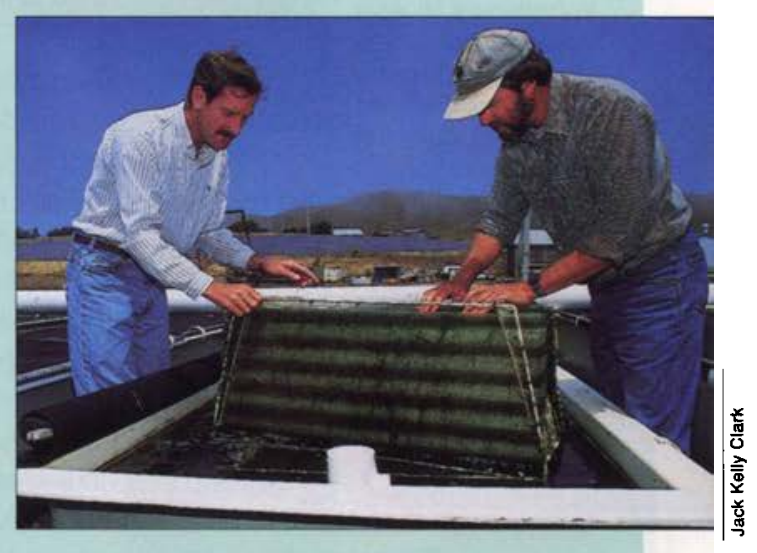
sheds reduced salinity levels in parts of Tomales Bay from the usual 32 parts per thousand to near zero. This 100 -year flood, coupled with a dramatic realignment of flow through the Walker Creek delta, caused thousands of abalone to die because they were unable to tolerate the low salinity. One grower reported losing 90,000 abalone - one-third of his total crop.

Abalone growers are considering various ways to prevent a recurrence of this disaster. One option is to move the abalone cages to deeper water, where they would be less exposed to the freshwater lens at the surface. Another possible solution is to wrap the cages to 


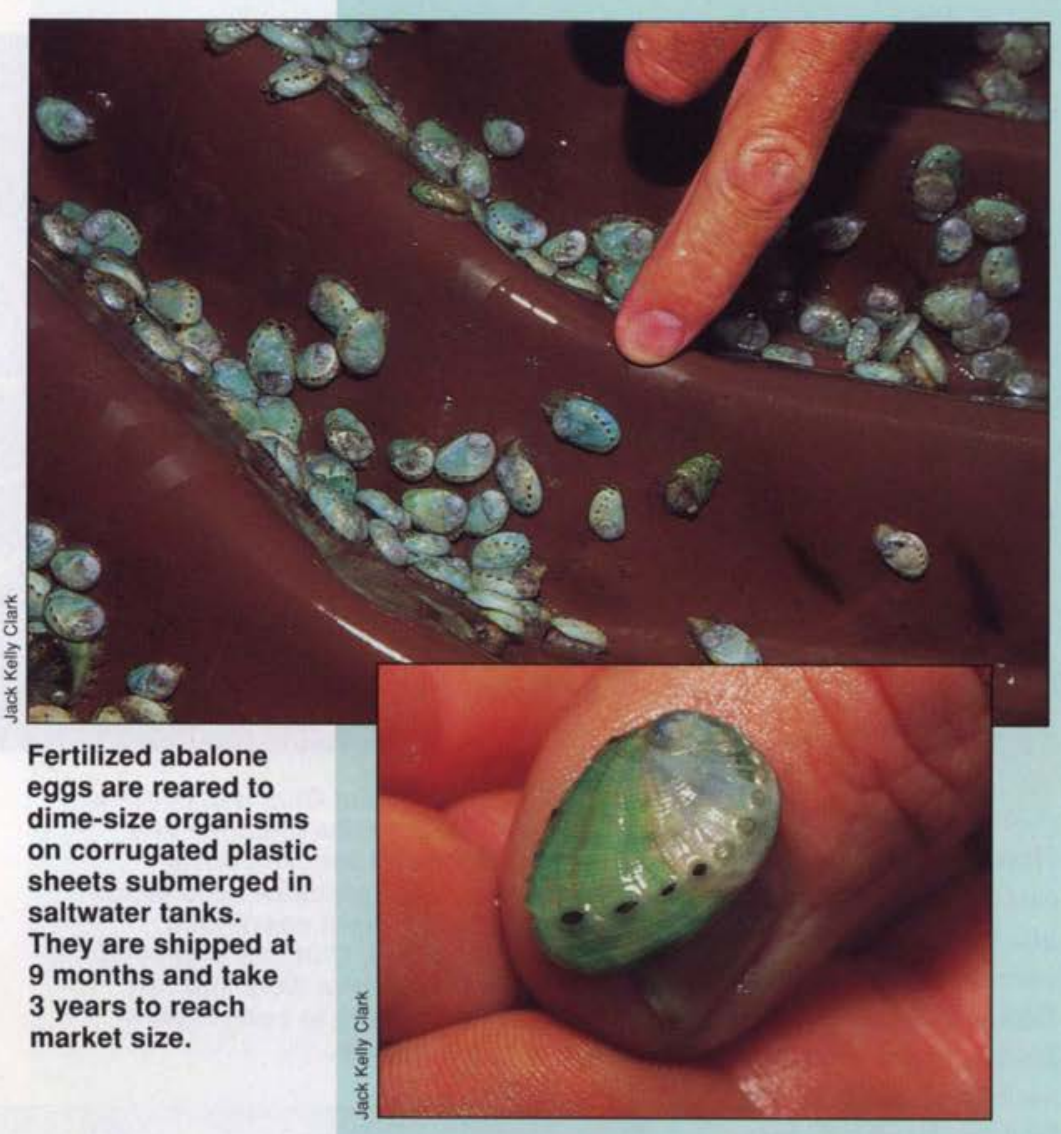

prevent the fresh water from entering them during these periods.

Meanwhile, the California Department of Fish and Game (CDFG) is struggling to protect the state's wild abalone populations. White abalone appear to be on the verge of extinction. Black abalone are suffering from a rickettsia-induced disease, called "withering syndrome," which has also been observed recently in other abalone species. Poaching is a major problem along the North Coast, where commercial harvesting and SCUBA-equipped sports diving have been banned for several decades.

For centuries, abalone have provided people with food and decorative shells used for adornment and trade. Today, the future of both cultured and wild stocks of abalone and other shellfish depends on sound management, clean water and habitat protection. To sustain abalone populations, it is important to implement sound management, reduce erosion and control nonpoint-source pollution from agricultural, residential and urban areas in order to protect coastal habitat and water quality.

P.G. Olin is Marine Advisor, UC Sea Grant Program, Sonoma County Cooperative Extension.

\section{continued from p. 6}

ton, appears doomed to extinction-one recent survey found 11 individuals, only one of which was female.

Mia Tegner, a research marine biologist at the Scripps Institution of Oceanography at UC San Diego, says there were many factors behind the state's failure to halt the demise of the abalone fishery. DFG biologists first recognized that abalone were in trouble in the 1970s. At that time, however, experts thought they could reverse the decline by seeding abalone beds with hatchery-reared juveniles. Unfortunately, says Tegner, optimism about the potential for seeding, which did not prove successful, was used to forestall actions to protect the fishery. Although some areas were closed and other actions taken to limit harvesting, abalone populations continued to decline. Poaching and inadequate funding for the DFG exacerbated the problem, Tegner says.

Predation by sea otters, whose population has expanded in recent decades, has reduced the abundance of abalone in certain areas; where sea otters are abundant, abalone are much less common and rarely attain harvestable size. But according to DFG biologists, sea otters are not a factor in the commercially harvested areas where abalone are most in need of protection. In Northern California, where commercial harvesting of abalone has been prohibited by state law since 1945, recreational harvesting by divers without SCUBA gear is still allowed and red abalone persist in sufficient numbers to support a very active sport fishery.

According to Treanor, the joint jurisdiction of the FGC and the Legislature has complicated management of abalone. For example, the Legislature had established in law the open and closed seasons for abalone, thereby constraining the FGC's ability to control the harvest more stringently by shortening the length of the open season. The FGC has authority to close a fishery for up to 2 years in a given area, but first it must have biological data demonstrating a problem, for which it usually relies on the DFG. The commission also holds public hearings before taking action so that interested parties can provide their input.

"The awkwardness of how fisheries are managed by the state can complicate mattersit's a very democratic process, and it takes a long time to reach a decision," says Cooperative Extension marine fisheries specialist Chris Dewees. 